Proceedings

\title{
Detection of Small Peptide Hormones for Anti- Doping Purpose via a Molecularly Imprinted Polymer-Based SPR Assay ${ }^{\dagger}$
}

\author{
Francesca Torrini, Pasquale Palladino, Simona Scarano* and Maria Minunni \\ Department of Chemistry, University of Florence, via della Lastruccia 3, 50019 Sesto Fiorentino, Italy; \\ * Correspondence: simona.scarano@unifi.it \\ + Presented at the 1st International Electronic Conference on Biosensors, 2-17 November 2020; Available \\ online: https://iecb2020.sciforum.net/.
}

Received: date; Accepted: date; Published: date

Keywords: polynorepinephrine; peptide hormones; anti-doping controls; competitive assay; optical sensing; surface plasmon resonance; epitope imprinting

Currently, there is a lack of low-cost, prompt and robust bioanalytical methods to detect small peptide hormones (e.g., gonadorelin, buserelin, leuprorelin, etc.) in the routine anti-doping protocol. These peptides are improperly used by male athletes to improve their sports performances by stimulating the endogenous secretion of testosterone in the bloodstream via the hypothalamicpituitary-gonadal axis. For this reason, low molecular weight peptide hormones $(<2000 \mathrm{Da})$ were banned by the World Anti-Doping Agency (WADA) and represent a new frontier in antidoping research. Our study aimed to design a molecularly imprinted polymer (MIP)-based assay to detect gonadorelin (pGlu-His-Trp-Ser-Tyr-Gly-Leu-Arg-Pro-Gly-NH2) levels in urine samples. The process of molecular imprinting involves the synthesis of a polynorepinephrine (PNE) network structure with imprinted template binding sites. The interaction between gonadorelin and the "tailor-made" synthetic receptor has been investigated and optimized through a surface plasmon resonance (SPR) platform. Afterward, a competitive biomimetic assay was set by employing biotinylated gonadorelin tethered to streptavidin as signal-enhancer competitor molecule. This type of assay is suitable for the detection of small molecules that lack multiple epitopes. Encouraging results were recorded for gonadorelin in buffer and spiked artificial urine samples (av\%recovery $=96.30 \%$ ) in the low-ppb range, perfectly in line with the Minimum Required Level (MRPL $=2 \mathrm{ppb})$ at which all WADAaccredited laboratories must operate in routine daily operations.

Moreover, we intend to provide a strategy to detect gonadorelin which can be easily miniaturized to set-up a sensing device for in-situ athletes' monitoring.

\section{References}

1. Baldoneschi, V.; Palladino, P.; Banchini, M.; Minunni, M.; Scarano, S. Biosens. Bioelectron. 2020, $157,112161$.

2. Available online: https://www.wada-ama.org (accessed on).

Publisher's Note: MDPI stays neutral with regard to jurisdictional claims in published maps and institutional affiliations.

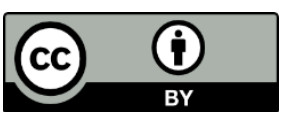

(C) 2020 by the authors. Submitted for possible open access publication under the terms and conditions of the Creative Commons Attribution (CC BY) license (http://creativecommons.org/licenses/by/4.0/). 